\title{
Effects of Yersinia enterocolitica infection on rabbit intestinal and colonic goblet cells and mucin: morphometrics, histochemistry, and biochemistry
}

\author{
M Mantle, E Atkins, J Kelly, E Thakore, A Buret, D G Gall
}

\begin{abstract}
The effects of Yersinia enterocolitica on intestinal goblet cells were investigated in New Zealand white rabbits. Animals infected with $Y$ enterocolitica were compared with weight matched and pair fed controls. Goblet cell hyperplasia developed in the distal small intestine of infected rabbits on day 1 , in the mid small intestine on day 3 , and in the upper small intestine on day 6. In all regions hyperplasia persisted throughout the 14 day study. The degree of hyperplasia was greater in the distal small intestine than the upper and mid regions. Goblet cells in the proximal colon of infected animals seemed to respond as those in the distal small intestine. Thus goblet cell hyperplasia developed more rapidly and to a greater extent in the ileocaecal region where mucosal injury was most severe. These changes resulted directly from $\boldsymbol{Y}$ enterocolitica infection since goblet cell numbers did not increase in pair fed controls. Histochemically, goblet cell mucins from infected rabbits were unchanged at either six or 14 days. Biochemical analysis, however, established that purified mucins from animals on day 6 after infection were less sialylated (in the small intestine) and more sulphated (in the small intestine and proximal colon). In addition, mucins from the distal small intestine and the proximal colon seemed to contain fewer but longer oligosaccharide chains.
\end{abstract}

The mammalian gastrointestinal tract is lined with a layer of mucus gel which is thought to protect the delicate underlying mucosa from potentially harmful material in the lumen. ${ }^{1}$ The principal component of mucus is a complex, high molecular weight $\left(>2 \times 10^{6}\right)$ glycoprotein (mucin) that is responsible for the characteristic viscoelastic properties of the secretion. In the small intestine and colon mucin is produced by epithelial goblet cells lining the crypts and villi. In a variety of diseases changes have been observed in intestinal mucin (production, composition, and structure) and in the histochemical staining properties of goblet cells. For example, mucin synthesis and secretion are apparently increased in cystic fibrosis ${ }^{23}$ and during parasitic infections, ${ }^{4}$ but are decreased in ulcerative colitis. ${ }^{56}$ Intestinal mucin composition, and possibly also its structure, is altered in cystic fibrosis. ${ }^{78}$ Histochemical studies have shown alterations in the proportion of neutral, sialo-, and sulpho-staining mucins in duodenal ulceration, ' ulcerative colitis and Crohn's disease, ${ }^{10}$ solitary ulcer syndrome," cystic fibrosis, ${ }^{2}$ carcinoma, ${ }^{12}{ }^{13}$ and in the parasitised small intestine. ${ }^{1+15}$ As yet, however, it is not clear how or why these changes occur nor whether they compromise the efficacy of the mucus gel barrier.

Recently we investigated the effects of Yersinia enterocolitica, a common cause of infectious diarrhoea in humans, on the production of intestinal and colonic mucin in the rabbit. ${ }^{16}$ Infection of rabbits is known to result in disease that resembles human yersiniosis both clinically and morphologically. ${ }^{17-20}$ Compared with uninfected and pair fed control rabbits, mucin synthesis and secretion were significantly increased on day 6 in the upper, mid, and distal small intestine and in the proximal colon of animals infected with $Y$ enterocolitica. The tissue mucin content of infected rabbits was also high, apparently due to goblet cell hypertrophy or hyperplasia, or both. Although the entire intestine was affected, the greatest changes in tissue mucin content and mucin production occurred in the distal small intestine and the proximal colon where mucosal damage and dysfunction are also most severe. ${ }^{16}$

In the present study we measured the development of goblet cell hypertrophy and hyperplasia in different regions of the rabbit intestinal tract at various times after infection with $Y$ enterocolitica. The histochemical staining properties of goblet cell mucin were also investigated at different times after infection to determine whether changes in goblet cell numbers and mucin production were associated with changes in mucin composition. Finally, using biochemical techniques, we examined whether the composition and macromolecular structure of purified intestinal and colonic mucin were altered at day 6 after infection when goblet cell hyperplasia and mucin hypersecretion were known to occur.

\section{Methods}

ANIMAL MODEL

Three groups of New Zealand white rabbits (500-600 g) were studied as previously described. ${ }^{16}$ All animals were initially quarantined for three to four days to ensure the absence of diarrhoea. After an overnight fast one group was infected with a human pathogenic strain of $Y$ enterocolitica (MCH 700S, serotype 0:3) by intragastric inoculation with $10^{10}$ colony forming units suspended in $10 \mathrm{ml} \mathrm{NaHCO}$. Food intake of infected animals was recorded daily. A second group of animals was paired to the infected group on day 0 by age and weight. Paired animals were 
inoculated with $10 \mathrm{ml} \mathrm{NaHCO}_{3}$ only and thereafter were daily fed the same amount of food as consumed by the weight matched infected rabbit. Infected and pair fed animals were assessed daily for weight gain and evidence of diarrhoea and stool excretion of $Y$ enterocolitica by plating rectal swabs on Salmonella-Shigella agar. After an overnight fast infected rabbits were killed by a lethal dose of Euthanyl (MTC Pharmaecuticals, Cambridge, Canada) on days $1,3,6,10$, or 14 of infection. Pair fed rabbits were examined on days 6 and 14. Animals in the third group consisted of unmanipulated controls that were weight matched to infected and pair fed rabbits on days 0,6 , and 14 . This experimental protocol was approved by the Animal Care Committee, University of Calgary.

\section{MORPHOLOGICAL AND HISTOCHEMICAL STUDIES}

After death the small intestine was rapidly removed and divided into three equal lengths constituting the upper, mid, and distal regions. Two segments ( $2 \mathrm{~cm}$ in length) were taken from the middle of each region of the gut. The first 25 $30 \mathrm{~cm}$ of the proximal colon was also removed and duplicate tissue segments $(2 \mathrm{~cm}$ each) were taken $10 \mathrm{~cm}$ and $20 \mathrm{~cm}$ distal to the caecum. One segment from each pair was fixed in Carnoy's fluid for up to three days while the other segment was fixed in formalin for a minimum of seven days.

Carnoy's fixed sections ( $5 \mu \mathrm{m}$ ) from $1,3,6$, 10 , and 14 day infected rabbits, 6 and 14 day pair fed animals, and 0,6 , and 14 day unmanipulated control rabbits were stained with periodic acidSchiff and haematoxylin to visualise goblet cells and nuclei respectively. Goblet cells and enterocytes were counted on six well orientated cryptvillus units per tissue segment from the upper, mid, and distal small intestine. The crypt base was identified by the presence of Paneth cells while the villus tip was identified by the extrusion of enterocytes. The number of goblet cells along each crypt-villus unit was calculated per 100 enterocytes. At least three animals were used in each experimental group at each time period investigated except in the case of 6 day infected and pair fed groups which comprised six rabbits. Since goblet cell and enterocyte numbers in control rabbits were not statistically different at the three time points studied, all data from control animals were pooled. Means (SEM) were determined from the total number of observations ( $n=54$ for control rabbits, $n=36$ for 6 day infected and pair fed animals, $n=18$ for other infected and pair fed groups) and means were compared by one way analysis of variance followed by Student's $t$ test.

Histochemical assessment of mucins was performed on tissue taken from infected, pair fed, and weight matched control rabbits on days six and 14 after infection. The following staining procedures were used on eight serial sections ( 5 $\mu \mathrm{m})$ cut from formalin fixed tissue: (a) Alcian blue at $\mathrm{pH} 1.0$ to detect sulphomucins; (b) Alcian blue at pH 2.5 to detect sulpho- and sialomucins; (c) the potassium hydroxide saponification-selective periodate oxidationSchiff $\left(\mathrm{KOH}-\mathrm{PA}^{\star}-\mathrm{S}\right)$ procedure which stains sialic acids magenta ${ }^{21}$; (d) the selective periodate oxidation-borohydride reduction-potassium hydroxide saponification-selective periodate oxidation-Thionin Schiff-potassium hydroxide saponification-borohydride reduction-PAS (PA*-Bh-KOH-PA*-T-KOH-Bh-PAS) procedure which stains neutral sugars with oxidisable vicinol diols magenta, substituted sialic acids blue, and mixtures of the two various shades of purple ${ }^{21}$; (e) the potassium hydroxide saponification-selective periodate oxidationThionin Schiff-potassium hydroxide saponification-borohydride reduction-PAS (KOH-PA*-T$\mathrm{KOH}-\mathrm{Bh}-\mathrm{PAS}$ ) procedure which stains neutral sugars with oxidisable vicinol diols magenta, substituted and unsubstituted sialic acids blue, and mixtures of the two components various shades of purple ${ }^{21} ;(f)$ the potassium hydroxide saponification-selective periodate oxidationborohydride reduction-Alcian blue, $\mathrm{pH} 1 \cdot 0$-PAS (KOH-PA*-Bh-AB 1-0-PAS) procedure which stains neutral sugars with oxidisable vicinol diols magenta, O-sulphate esters aqua, and mixtures of the two purple ${ }^{21} ;(\mathrm{g})$ the potassium hydroxide saponification-selective periodate oxidationborohydride reduction-PAS (KOH-PA*-BhPAS) procedure which stains neutral sugars magenta ${ }^{21}$; and (h) the potassium hydroxide saponification-selective periodate oxidationAlcian blue, pH 1.0-Schiff (KOH-PA*-AB $1 \cdot 0-S)$ procedure which stains sialic acids magenta, $\mathrm{O}$-sulphate esters aqua, and mixtures of the two various shades of purple..$^{23}$ For each different staining protocol, appropriate experimental controls were carried out. ${ }^{21-23}$

Overall assessment of inflammation was carried out by an experienced pathologist (JK). Haematoxylin and eosin stained tissue sections from the upper, mid, and distal small intestine and the proximal colon of infected, pair fed, and control rabbits were examined at varying times $(1,3,6,10$, and 14 days) after infection. The pathologist was unaware of the treatment group to which the slides under evaluation belonged. Particular attention was paid to the presence or absence of inflammatory foci and bacterial abscesses.

\section{BIOCHEMICAL CHARACTERISATION OF PURIFIED} MUCIN

Mucin was purified from the upper, mid, and distal small intestine and the proximal colon of infected and unmanipulated control rabbits on day six after infection, as described previously..$^{2+}$ The monosaccharide composition of mucin hydrolysates was determined by gas-liquid chromatography. ${ }^{25}$ The sulphate content of mucins was measured by the method of Silvestri et al. ${ }^{26}$ The protein content and amino acid composition of mucins were established after hydrolysis in $6 \mathrm{~mol} / 1 \mathrm{HCl}$ for 24 hours at $110^{\circ} \mathrm{C}$ in vacuo and application of hydrolysates to a Beckman 6300 amino acid analyser (Beckman Instruments, Palo Alto (CA). The disulphide bond (S-S) and free thiol (-SH) content of mucins was determined by the method of Mantle et al. ${ }^{27}$ DNA was estimated by the method of Hinegardner. ${ }^{28}$ The immunoreactivity of purified mucins with antirabbit 


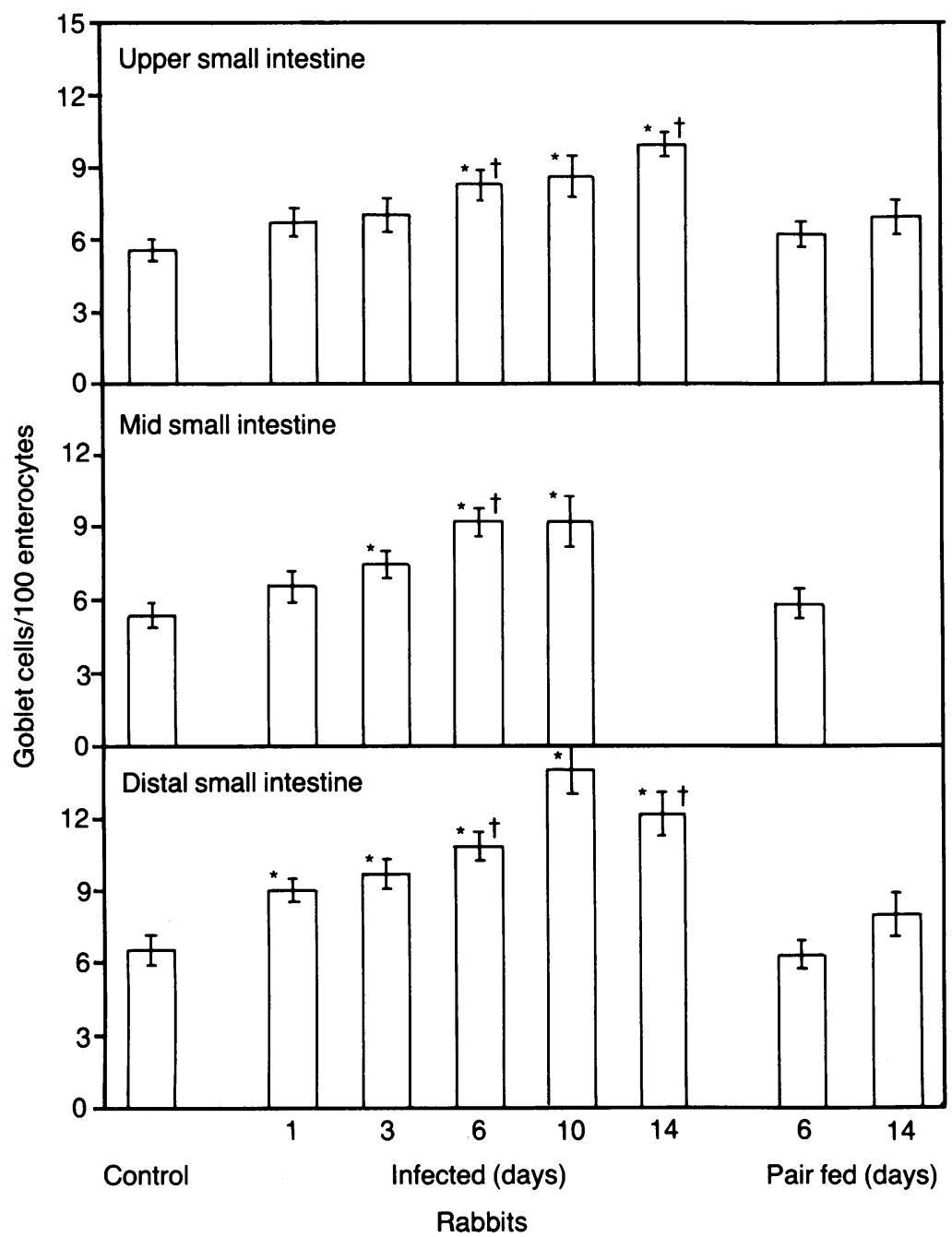

Figure 1: Development of goblet cell hyperplasia in Yersinia infected rabbits. Tissue sections, stained with periodic acid-Schiff and haematoxylin, were examined from the upper, mid, and distal small intestine of infected and pair fed rabbits at the times indicated, and unmanipulated weight matched control animals. Goblet cell numbers are expressed as percentage of the total enterocytes per crypt-villus unit (mean $(S E M))$. ${ }^{\star} p<0.05$ for infected compared with control rabbits; $\nmid p<0.05$ for infected compared with pair fed rabbits at the appropriate times (either 6 or 14 days). of which contained visible bacterial colonies. Inflammation and bacterial abscesses became more apparent in all regions of the gut during days 3 and 6 but remained patchy in distribution. Inflammatory foci were located in the mucosa in the upper region of the crypt and were often associated with epithelial ulceration and proliferation of bacteria in the lamina propria. The muscularis was free of involvement.

Inflammation and bacterial abscesses persisted in the distal small intestine and the proximal colon throughout the study period, becoming more diffuse in appearance, but cleared from the upper and mid small intestine by days $10-14$. These pathological changes were similar to those previously reported. ${ }^{17} 18$ All four regions of the intestinal tract of pair fed and control rabbits were free of inflammation at all times studied.

DEVELOPMENT OF GOBLET CELL HYPERPLASIA

The number of goblet cells and enterocytes per crypt-villus unit was determined in tissue from the upper, mid, and distal small intestine of infected and pair fed rabbits on days $1,3,6,10$, and 14 of the study. Compared with control animals the goblet cell to enterocyte ratios in infected rabbits were significantly increased in the distal small intestine by day 1 , in the mid small intestine by day 3 , and in the upper small intestine by day 6 (Fig 1 ). In all three regions of the gut, goblet cell hyperplasia persisted until day 14 after infection. These changes resulted from an absolute increase in goblet cells since enterocyte numbers per crypt-villus unit did not change in any region of the intestine of infected rabbits throughout the 14 day study period (Fig 2). In 6 and 14 day pair fed animals, goblet cell to enterocyte ratios and enterocytes per crypt-villus unit were not significantly different from control values in any region of the gut (Figs 1 and 2). The degree of hyperplasia showed a graded response down the intestinal tract of infected rabbits: the increase in goblet cell numbers after day 6 became progressively greater from the upper small intestine (showing a $45 \%$ increase) to the distal small intestine (a 70\% increase). Although we could not accurately quantitate goblet cells in the proximal colon of infected, pair fed, and control rabbits due to the more complex morphology of the tissue, light microscopy showed an increase in goblet cell numbers by day 1 in infected animals which persisted for the duration of the study, a pattern similar to that seen in the distal small intestine. evidence of diarrhoea and were free of any apparent infection. Infected and pair fed rabbits failed to thrive: body weights did not significantly increase over day 0 values (mean (SEM) infected 540 (31) g; pair fed $550(24) \mathrm{g}$ ) at any time during the 14 day study period. On the day of study, the body weights of animals in infected, pair fed, and control groups were not significantly different.

The upper, mid, and distal small intestine and the proximal colon of infected rabbits showed patchy foci of acute inflammation on day 1 , most

\section{HISTOCHEMICAL ASSESSMENT OF GOBLET CELL MUCIN}

Goblet cells in tissue sections from the upper, mid, and distal small intestine of infected rabbits on day 6 stained aqua with Alcian blue at both $\mathrm{pH} 1.0$ and $2 \cdot 5$, indicating the presence of $\mathrm{O}$-sulphate esters and sialic acid groups. The presence of sialic acid was confirmed by the magenta stain on sections processed through the KOH-PA*-S procedure. Sections treated with the PA*-Bh-KOH-PA*-T-KOH-Bh-PAS and the $\mathrm{KOH}-\mathrm{PA}^{\star}-\mathrm{T}-\mathrm{KOH}-\mathrm{Bh}-\mathrm{PAS}$ procedures 


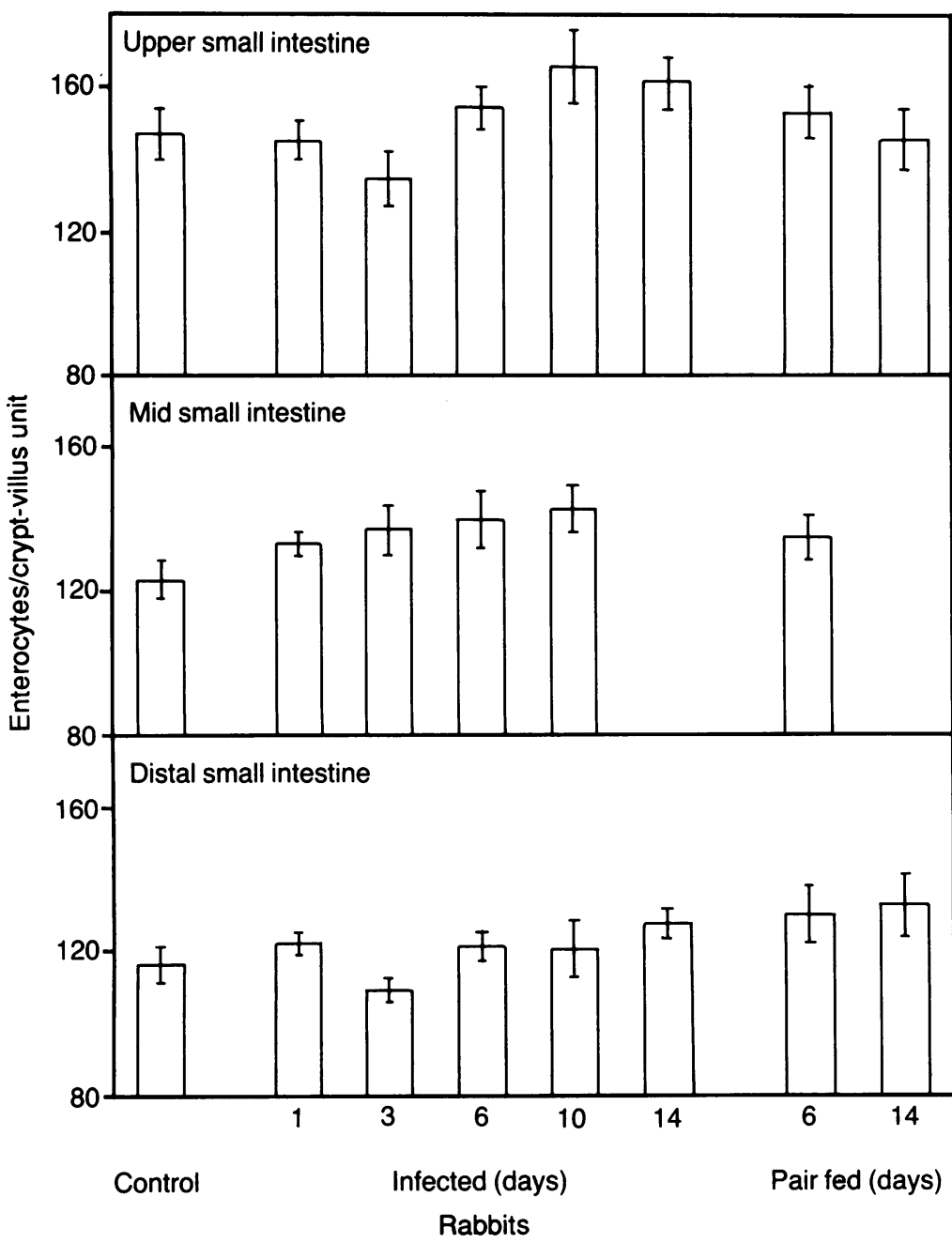

Figure 2: Enterocytes per crypt-villus unit in Yersinia infected rabbits. Enterocytes per cryptvillus unit (mean (SEM)) were determined from the same tissue sections used in Figure 1. No significant differences were detected between infected, pair fed, and unmanipulated, weight matched control rabbits at the different times studied.

stained predominantly red to red/purple, indicating the presence of neutral sugars and some sialic acid. Sections from the KOH-PA*Bh-AB 1.0-PAS procedure stained predominantly royal blue though some aqua and purple goblet cells were also seen, indicating that both neutral sugars and $\mathrm{O}$-sulphate esters were present. Treatment of sections with the $\mathrm{KOH}$ $\mathrm{PA}^{\star}$-Bh-PAS procedure stained all goblet cells an intense magenta shade, confirming the presence of neutral sugars. Sections processed through the $\mathrm{KOH}-\mathrm{PA}^{\star}-\mathrm{AB} 1 \cdot 0-\mathrm{S}$ procedure appeared predominantly aqua, indicating that goblet cells contained largely $\mathrm{O}$-sulphate esters. Thus, 6 day infected rabbits produced goblet cell mucin containing relatively large quantities of $O$-sulphate esters and neutral sugars having oxidisable vicinol diols, with some sialic acids also being present. The staining profile of goblet cells in infected animals did not vary down the length of the small intestine nor along the cryptvillus unit.

In tissues from the proximal colon (10 and 20 $\mathrm{cm}$ distal to the caecum) of 6 day infected rabbits, goblet cells in the crypts and on the surface epithelium stained aqua with Alcian blue at $\mathrm{pH} 2 \cdot 5$, indicating the presence of both sulpho- and sialomucins. Sections from both regions of the proximal colon stained red-purple in the PA ${ }^{\star}-\mathrm{Bh}-\mathrm{KOH}-\mathrm{PA}^{\star}-\mathrm{T}-\mathrm{KOH}-\mathrm{Bh}-\mathrm{PAS}$ and the $\mathrm{KOH}-\mathrm{PA}^{\star}-\mathrm{T}-\mathrm{KOH}-\mathrm{Bh}-\mathrm{PAS}$ procedures, reflecting the presence of neutral sugars with some sialic acid residues.

In tissue taken $10 \mathrm{~cm}$ along the proximal colon, all goblet cells along the length of the crypts stained an intense shade of magenta with the $\mathrm{KOH}-\mathrm{PA}^{\star}$-Bh-PAS, reflecting the widespread presence of neutral sugars. Using the $\mathrm{KOH}-\mathrm{PA}^{\star}$-Bh-AB 1.0-PAS technique, upper crypt and surface goblet cells stained predominantly purple to royal blue, indicating the presence of both neutral sugars and $\mathrm{O}$-sulphate esters. Lower crypt goblet cells appeared redpurple, suggesting a relatively lower content of $\mathrm{O}$-sulphate esters. By the $\mathrm{KOH}-\mathrm{PA}^{\star}$-AB 1.0-S procedure, upper crypt and surface goblet cells stained royal blue, indicating $\mathrm{O}$-sulphate esters and some sialic acid residues, but lower crypt goblet cells stained predominantly red-purple, again suggesting a relatively lower content of sulphate groups. These results were confirmed using Alcian blue at $\mathrm{pH} 1.0$ when goblet cells in the upper crypt region and on the surface stained intensely aqua for sulphate residues but lower crypt goblet cells were essentially unstained. Conversely, upper crypt and surface goblet cells failed to stain by the KOH-PA*-S procedure for sialic acid residues, but those in the lower two thirds of the crypts stained intensely magenta. Thus in this section of the colon neutral sugars were uniformly distributed throughout all goblet cells, $\mathrm{O}$-sulphate esters occurred largely in upper crypt and surface goblet cells, and sialic acid residues were mostly confined to lower crypt goblet cells. These results are in agreement with previous histochemical studies describing the staining properties of rabbit colonic goblet cells. ${ }^{29}$

Differences were observed in tissue taken 20 $\mathrm{cm}$ distal to the caecum. Goblet cells stained either intensely or only faintly magenta with the $\mathrm{KOH}-\mathrm{PA}^{\star}$-Bh-PAS procedure indicating the presence of either relatively high or relatively low amounts of neutral sugars respectively. The sulphate and sialic acid gradients seen in tissue taken $10 \mathrm{~cm}$ along the proximal colon were not apparent in more distal tissue. Goblet cells staining intensely aqua with Alcian blue at $\mathrm{pH}$ 1.0 were patchily distributed along the crypts and on the surface. Similarly, the KOH-PA*-S procedure for sialic acid residues stained clusters of goblet cells intensely magenta, but other goblet cells along the crypts and on the surface epithelium failed to stain. With the KOH-PA* Bh-AB 1-0-PAS technique goblet cells along the entire length of the crypts stained either intensely aqua or intensely purple, producing a mottled distribution of sulphate esters and sialic acid groups. The $\mathrm{KOH}-\mathrm{PA}^{\star}-\mathrm{AB} \quad 1 \cdot 0-\mathrm{S}$ procedure stained goblet cells predominantly aqua, reflecting $\mathrm{O}$-sulphate esters, but some cells stained a faint shade of purple, confirming the presence of sialic acid residues. Thus, neutral sugars, ester sulphate groups, and sialic acid residues were all present in the tissue but their distribution in goblet cells was patchy and uneven.

The histochemical staining profile of mucin in all regions of the gut described above for 6 day infected rabbits was identical to that in pair fed 
TABLE I Amino acid composition of purified mucins isolated from Yersinia infected and control rabbits

\begin{tabular}{|c|c|c|c|c|c|c|c|c|}
\hline & \multicolumn{4}{|c|}{ Infected rabbits } & \multicolumn{4}{|l|}{ Control rabbits } \\
\hline & $\begin{array}{l}\text { Upper small } \\
\text { intestine } \\
(\text { mol/100 mol })\end{array}$ & $\begin{array}{l}\text { Mid small } \\
\text { intestine } \\
(\text { mol/100 mol })\end{array}$ & $\begin{array}{l}\text { Distal small } \\
\text { intestine } \\
(\text { mol/100 mol })\end{array}$ & $\begin{array}{l}\text { Proximal } \\
\text { colon } \\
(\mathrm{mol} / 100 \mathrm{~mol})\end{array}$ & $\begin{array}{l}\text { Upper small } \\
\text { intestine } \\
(\text { mol/100 mol })\end{array}$ & $\begin{array}{l}\text { Mid small } \\
\text { intestine } \\
(\text { mol/100 mol })\end{array}$ & $\begin{array}{l}\text { Distal small } \\
\text { intestine } \\
(\text { mol/100 mol })\end{array}$ & $\begin{array}{l}\text { Proximal } \\
\text { colon } \\
(\mathrm{mol} / 100 \mathrm{~mol})\end{array}$ \\
\hline \multirow{20}{*}{$\begin{array}{l}\text { Aspartic acid } \\
\text { Threonine } \\
\text { Serine } \\
\text { Glutamic acid } \\
\text { Proline } \\
\text { Glycine } \\
\text { Alanine } \\
\text { Valine } \\
\text { Methionine } \\
\text { Isoleucine } \\
\text { Leucine } \\
\text { Tyrosine } \\
\text { Phenylalanine } \\
\text { Histidine } \\
\text { Lysine } \\
\text { Arginine } \\
\text { \% protein } \\
\text { S-S (nmol)/mg } \\
\text { mucin } \\
\text {-SH (nmol)/mg } \\
\text { mucin }\end{array}$} & $7 \cdot 5$ & $7 \cdot 8$ & 8.0 & $7 \cdot 1$ & $7 \cdot 7$ & 6.4 & 6.9 & $6 \cdot 7$ \\
\hline & $23 \cdot 4$ & 20.4 & 23.7 & 20.6 & $22 \cdot 5$ & $22 \cdot 8$ & $22 \cdot 4$ & 21.7 \\
\hline & $7 \cdot 3$ & $7 \cdot 6$ & 8.9 & $10 \cdot 2$ & $8 \cdot 4$ & $7 \cdot 5$ & $8 \cdot 7$ & $8 \cdot 7$ \\
\hline & $9 \cdot 6$ & $9 \cdot 8$ & $9 \cdot 4$ & $9 \cdot 4$ & $8 \cdot 3$ & $7 \cdot 8$ & $8 \cdot 4$ & $9 \cdot 6$ \\
\hline & $13 \cdot 3$ & 11.9 & $11 \cdot 0$ & $11 \cdot 1$ & $12 \cdot 6$ & 13.0 & $10 \cdot 9$ & 11.9 \\
\hline & $7 \cdot 2$ & $7 \cdot 0$ & 6.5 & 6.4 & 7.8 & $7 \cdot 7$ & 6.6 & $6 \cdot 6$ \\
\hline & $6 \cdot \overline{1}$ & 5.6 & $6 \cdot 3$ & $5 \cdot 5$ & $7 \cdot 5$ & $8 \cdot 1$ & $8 \cdot 7$ & $6 \cdot 2$ \\
\hline & $5 \cdot 4$ & $5 \cdot 8$ & $5 \cdot 4$ & $5 \cdot 3$ & $5 \cdot 0$ & $5 \cdot 6$ & $5 \cdot 6$ & 6.0 \\
\hline & $0 \cdot 2$ & 0.3 & 0.5 & 0.5 & 0.6 & 0.6 & $1 \cdot 3$ & 0.7 \\
\hline & $2 \cdot 1$ & $2 \cdot 8$ & $2 \cdot 8$ & $2 \cdot 7$ & $2 \cdot 3$ & $3 \cdot 4$ & 2.9 & $2 \cdot 4$ \\
\hline & $5 \cdot 5$ & 6.4 & $5 \cdot 7$ & $6 \cdot 2$ & $5 \cdot 3$ & $5 \cdot 0$ & $5 \cdot 8$ & $6 \cdot 0$ \\
\hline & $2 \cdot 4$ & $3 \cdot 3$ & $2 \cdot 6$ & $2 \cdot 5$ & $2 \cdot 3$ & 1.9 & $2 \cdot 1$ & $2 \cdot 4$ \\
\hline & $2 \cdot 4$ & $2 \cdot 5$ & $2 \cdot 5$ & $2 \cdot 6$ & $2 \cdot 0$ & 1.9 & $2 \cdot 3$ & $2 \cdot 0$ \\
\hline & $1 \cdot 6$ & $1 \cdot 7$ & 1.9 & $2 \cdot 1$ & 1.9 & $1 \cdot 4$ & $1 \cdot 2$ & $1 \cdot 7$ \\
\hline & $3 \cdot 3$ & $3 \cdot 7$ & $3 \cdot 3$ & 3.9 & $3 \cdot 6$ & $3 \cdot 3$ & $2 \cdot 4$ & $3 \cdot 2$ \\
\hline & $3 \cdot 2$ & $3 \cdot 7$ & $3 \cdot 4$ & $3 \cdot 5$ & 3.8 & $3 \cdot 2$ & $3 \cdot 4$ & $4 \cdot 1$ \\
\hline & $16 \cdot \overline{7}$ & $18 \cdot 8$ & $17 \cdot 9$ & $12 \cdot 8$ & $18 \cdot 4$ & $18 \cdot 6$ & $20 \cdot 3$ & 20.9 \\
\hline & $100 \cdot 0$ & 93.0 & $60 \cdot 0$ & $38 \cdot 0$ & $88 \cdot 0$ & $101 \cdot 0$ & $79 \cdot 0$ & $117 \cdot 0$ \\
\hline & & & & & & & 110 & 0.0 \\
\hline & $8 \cdot 0$ & $11 \cdot 0$ & $12 \cdot 0$ & $13 \cdot 0$ & 16.0 & 1.0 & $11 \cdot 0$ & 9.0 \\
\hline
\end{tabular}

Mucins were purified from the four regions of the gut of infected and unmanipulated control rabbits on day 6 after infection. The protein content of each mucin was calculated from amino acid analyses and is presented as the percentage dry weight. Average results from duplicate analyses on three independent preparations of each mucin are presented.

and control animals. Even after 14 days the histochemical properties of goblet cells in infected and pair fed animals were not different from those of control rabbits in any region of the gut. It was therefore not possible to distinguish either experimental group (infected or pair fed) from control animals on the basis of mucin histochemistry at any time after infection.

\section{BIOCHEMICAL CHARACTERISATION OF PURIFIED MUCIN}

Mucins were purified from the upper, mid, and distal small intestine and the proximal colon of 6 day infected and unmanipulated control rabbits by equilibrium density gradient centrifugation in $\mathrm{CsCl}$ (twice) and gel filtration on Sepharose 2B. ${ }^{24}$ Mucins from both infected and control rabbits showed the same buoyant density on $\mathrm{CsCl}$ gradients $(1.4 \mathrm{~g} / \mathrm{ml})$ and the same elution profile on Sepharose 2B columns, with $>80 \%$ of

TABLE II Carbohydrate profiles of purified mucins from Yersinia infected and control rabbits

\begin{tabular}{|c|c|c|c|c|}
\hline & $\begin{array}{l}\text { Upper small } \\
\text { intestine } \\
(\text { mol/100 mol })\end{array}$ & $\begin{array}{l}\text { Mid small } \\
\text { intestine } \\
(\text { mol/100 mol })\end{array}$ & $\begin{array}{l}\text { Distal small } \\
\text { intestine } \\
(\text { mol/100 mol })\end{array}$ & $\begin{array}{l}\text { Proximal } \\
\text { colon } \\
\text { (mol/100 mol) }\end{array}$ \\
\hline \multicolumn{5}{|l|}{ Infected: } \\
\hline Fucose & $9 \cdot 4$ & 9.9 & $14 \cdot 2$ & $10 \cdot 4$ \\
\hline Mannose & $2 \cdot 0$ & $2 \cdot 0$ & 1.9 & $1 \cdot 7$ \\
\hline Galactose & $24 \cdot 0$ & $25 \cdot 4$ & $31 \cdot 2$ & $33 \cdot 2$ \\
\hline GlcNAc & $27 \cdot 1$ & $27 \cdot 5$ & $24 \cdot 3$ & $25 \cdot 3$ \\
\hline GalNAc & $26 \cdot 3$ & $25 \cdot 4$ & $18 \cdot 2$ & $10 \cdot 0$ \\
\hline Sialic acid & $11 \cdot 2$ & $9 \cdot 9$ & $9 \cdot 5$ & $19 \cdot 4$ \\
\hline Sulphate & $13 \cdot 9$ & $12 \cdot 8$ & $19 \cdot 1$ & $15 \cdot 4$ \\
\hline $\mathrm{S}+\mathrm{T} / \mathrm{GalNac}$ & $1 \cdot 3$ & $1 \cdot 3$ & 1.5 & $1 \cdot 7$ \\
\hline $\mathrm{B}_{50}$ (range) & $19(14-24)$ & $16(12-20)$ & $16(6-21)$ & $12(8-20)$ \\
\hline $\begin{array}{l}\text { Control: } \\
\text { Fucose }\end{array}$ & $9 \cdot 5$ & $9 \cdot 0$ & $9 \cdot 9$ & $10 \cdot 3$ \\
\hline Mannose & $2 \cdot 1$ & $2 \cdot 0$ & 1.6 & 1.8 \\
\hline Galactose & $21 \cdot 6$ & 21.9 & $22 \cdot 7$ & $23 \cdot 7$ \\
\hline GlcNAc & 21.9 & $21 \cdot 1$ & $21 \cdot 1$ & $21 \cdot 1$ \\
\hline GalNAc & $28 \cdot 4$ & $29 \cdot 8$ & $29 \cdot 7$ & $20 \cdot 2$ \\
\hline Sialic acid & $16 \cdot 4$ & $16 \cdot 0$ & $15 \cdot 0$ & $22 \cdot 9$ \\
\hline Sulphate & 5.9 & $6 \cdot 2$ & 6.8 & $5 \cdot 3$ \\
\hline $\mathrm{S}+\mathrm{T} / \mathrm{GalNac}$ & $1 \cdot 1$ & 1.0 & 0.9 & 0.8 \\
\hline $\mathrm{B}_{50}$ (range) & $29(15-37)$ & $26(15-34)$ & $18(10-26)$ & $16(8-28)$ \\
\hline
\end{tabular}

Mucins were purified from the four regions of the gut of infected and control rabbits on day 6 after infection. Sulphate data are expressed as mol/100 mol of sugar. $\mathrm{S}+\mathrm{T} / \mathrm{GalNac}=$ ratio of serine plus
threonine to $N$-acetylgalactosamine; GlcNAc $=N$-acetylglucosamine; $\mathrm{B}_{50}=$ amount of mucin (in ng) threonine to $N$-acetylgalactosamine; GlcNAc $=N$-acetylglucosamine; $B_{50}=$ amount of mucin (in $\mathrm{ng}$ )
required to produce half maximal binding in an enzyme linked immunosorbent assay using a highly required to produce half maximal binding in an enzyme linked immunosorbent assay using a high specific antirabbit intestinal mucin antibody. Data for control rabbits are taken from Mantle Thakore. ${ }^{24}$ All data represen
preparations of each mucin. the mucin being recovered in the void volume fractions (data not shown). Purified mucins were free of detectable DNA $(<2 \mu \mathrm{g} / \mathrm{mg}$ glycoprotein) and contaminating protein (as assessed by the absence of silver-staining bands on sodium dodecylsulphate-polyacrylamide gel electrophoresis under non-reducing conditions). ${ }^{24}$ The amino acid composition of purified mucins from infected rabbits did not differ from that of control mucins (Table I). Although unchanged in small intestinal mucins, the total protein and S-S bond content of mucin from the proximal colon of infected rabbits was decreased relative to that of control mucin. Differences were observed in the carbohydrate profiles of mucins from infected and control animals, but the nature of the changes varied somewhat down the length of the gut (Table II). Compared with control mucins the sialic acid content of infected mucins from the upper and mid small intestine was decreased by $5-6 \mathrm{~mol} / 100 \mathrm{~mol}$ with a corresponding increase in the $N$-acetylglucosamine content. In addition to these changes, mucin from the distal small intestine of infected rabbits showed a small increase in fucose and a pronounced shift in $N$-acetylgalactosamine and galactose content. In mucin from the proximal colon, $N$-acetylgalactosamine was reduced in infected animals while $N$-acetylglucosamine and particularly galactose were increased. The change in $N$-acetylgalactosamine content of infected mucins from the distal small intestine and the proximal colon resulted in a change in the ratio of this sugar to serine plus threonine (Table II). Mucins from all four regions of the gut of infected rabbits had an appreciably higher sulphate content than those isolated from control animals (Table II). These changes were seen consistently in three independent mucin preparations from infected and control rabbits. Despite the compositional differences, infected and control mucins reacted identically with an anti-mucin antibody in an enzyme linked immunosorbent assay (Table II). All mucins produced parallel slopes in the assay, indicating the same affinity for the antibody, and $B_{50}$ values 
(the amount of mucin required to produce halfmaximal antibody binding, ${ }^{24}$ were also the same for infected and control mucins, indicating equal numbers of antigenic determinants.

\section{Discussion}

The purpose of this study was to monitor goblet cells in the upper, mid, and distal small intestine and the proximal colon of rabbits at varying times after infection with $Y$ enterocolitica and to establish whether infection caused changes in the histochemistry and biochemistry of goblet cell mucin. An increase in goblet cell numbers per crypt-villus unit was detected in the distal small intestine of infected animals as early as day 1 after infection, in the mid small intestine by day 3 , and in the upper small intestine by day 6 . In al three regions goblet cell hyperplasia persisted throughout the 14 day study period. The relative degree of hyperplasia also showed a graded response down the intestinal tract, being greater in the distal than in the mid and upper small intestine. Although goblet cells in the proximal colon were not quantitated, they seemed to respond to infection in the same manner as those in the distal small intestine. Since earlier studies showed that $Y$ enterocolitica infection caused more damage and dysfunction in the ileocaecal region of the gut than in the upper and mid smal intestine,${ }^{18} 20$ our findings suggest that goblet cell hyperplasia develops more rapidly and to a greater extent in those areas of the intestine where mucosal injury is most severe.

In previous studies the tissue mucin content of the upper, mid, and distal small intestine of $Y$ enterocolitica-infected rabbits was found to increase three to fourfold on day 6 as assessed using a highly specific mucin immunoassay. ${ }^{16}$ Since goblet cell numbers in infected animals at day 6 increased to a lesser extent (roughly twofold) over control levels, it seems that hypertrophy as well as hyperplasia of goblet cells occurs in the $Y$ enterocolitica-infected small intestine.

The changes observed in $Y$ enterocoliticainfected rabbits did not arise as a result of their decreased good intake and impaired weight gain. Pair fed animals examined on days 6 and 14 showed no evidence of goblet cell hypertrophy and hyperplasia in any region of the gut when compared with unmanipulated cöntrol rabbits. These results are in agreement with previous studies which also showed no differences between pair fed and control rabbits in terms of their immunoreactive tissue mucin content. ${ }^{16}$ Thus development of goblet cell hypertrophy and hyperplasia in infected rabbits can be directly attributed to the presence of $Y$ enterocolitica.

Despite the changes in goblet cell size and number in infected rabbits, a battery of eight different histochemical stains failed to detect an alteration in the staining profile of mucin at either day 6 or 14, suggesting that the carbohydrate and sulphate components of mucin are not affected by the disease process. These results were surprising, not only in view of the hyperplastic and hypertrophic changes in goblet cells and the pronounced increases in mucin synthesis and secretion in infected rabbits, ${ }^{16}$ but also because alterations in mucin histochemistry frequently occur in diseases that affect the gastrointestinal tract - for example, carcinoma, ${ }^{12}{ }^{13}$ inflammatory bowel disease, ${ }^{510}$ cystic fibrosis, ${ }^{2}$ and parasitic infections. ${ }^{1415}$ While it may be argued that the duration of our experiments was not sufficiently long for changes in mucin composition to occur, this seems unlikely since alterations in mucin histochemistry have been noted in the intestine of rats infected with Nippostrongylus brasiliensis after only 10 days $^{14}$ and biochemical studies (see below) indicate that mucin composition was altered in $Y$ enterocolitica-infected rabbits after just 6 days.

Since the histochemical findings were so unexpected we used biochemical techniques to examine mucin composition in infected rabbits. The chemical composition of purified mucins from the upper, mid, and distal small intestine and the proximal colon of infected animals was compared with mucins isolated from unmanipulated control rabbits on day 6 of the study since at this time goblet cell hypertrophy and hyperplasia and mucin hypersecretion are well developed in all four regions of the gut of infected rabbits. Contrary to histochemical observations, changes were detected in the carbohydrate profiles and sulphate contents of mucins isolated from infected rabbits. Throughout the small intestine, the sialic acid content of mucins from infected animals was decreased. Conversely, an increase was observed in mucin sulphate content in all four regions of the gut examined. It seems likely that these changes were not detected histochemically because control mucins are so heavily sialylated and sulphated that alterations in the amount of these residues present would not be capable of producing an appreciable and clearly visible shift in the staining pattern of the mucin.

Further changes in composition were observed in mucins isolated from the distal small intestine and the proximal colon of infected rabbits. The $N$-acetylgalactosamine content of these mucins was appreciably reduced compared with that in control mucins, but the amounts of galactose and to a lesser extent $N$ acetylglucosamine and fucose (in the distal small intestine only) were increased. Similar findings in mucins isolated from patients with cystic fibrosis were previously interpreted to suggest a change in mucin glycosylation leading to the production of longer, more branched oligosaccharide chains. ${ }^{7}$ Since the ratio of serine and threonine to $N$-acetylgalactosamine increased in mucins from the infected distal small intestine and proximal colon, it seems that fewer serine and theronine residues in these mucins are glycosylated - that is, they contained less but longer sugar side chains. The reduced protein content of mucin from the proximal colon of infected rabbits, coupled with the altered ratio of serine and threonine to $\mathrm{N}$-acetylgalactosamine, suggest that glycosylation may be appreciably changed in this mucin. Perhaps the higher biosynthetic and secretory activity of goblet cells in the distal small intestine and the proximal colon of infected animals leads to the lower substitution of serine and threonine residues 
but a greater opportunity for oligosaccharide branching or elongation.

In spite of the changes in composition, mucins from infected rabbits retained the same buoyant density on $\mathrm{CsCl}$ gradients as control mucins and eluted in the void volume fractions of a Sepharose 2B column. This latter observation suggests that goblet cells in infected rabbits still produce high molecular weight, polymeric mucin and not small monomers which would be included by Sepharose $2 \mathrm{~B} .{ }^{24}$ Given the large increase in the rate of mucin synthesis and secretion throughout the gut of infected rabbits and the fact that mucin from the proximal colon had a diminished protein content and fewer S-S bonds than control mucin, it might have been expected that smaller, less polymerised mucin would be produced in infected animals.

In an attempt to relate the changes in goblet cells with mucosal injury and inflammatory processes, tissue sections from infected rabbits were examined for bacterial microabscesses and inflammatory infiltration. Foci of inflammation, usually (but not always) associated with bacterial abscesses, were apparent in all regions of the gut of infected rabbits as early as day 1 . Inflammation and abscesses persisted in the distal small intestine and the proximal colon throughout the 14 day study period, gradually becoming more widespread and diffuse, but cleared from the upper and mid small intestine by about 10 days. No attempts were made in the present study to count cells in the inflammatory infiltrate in infected rabbits, although the majority were granulocytes (previously identified as neutrophils/pseudo-eosinophils). ${ }^{30}$ Since all regions of the gut of infected rabbits seemed to be equally affected during the early stages of the disease, it is not clear why goblet cell hyperplasia developed earlier in the distal small intestine and the proximal colon than in the upper and mid small intestine. Possibly inflammatory cell mediators or bacterial products, or both, accumulated more rapidly in the ileocaecal region, thus initiating the proliferative response of goblet cells.

In view of our findings it was of interest to relate them to earlier work on the effects of $Y$ enterocolitica-infection on intestinal function in the rabbit. ${ }^{18}$ Significant decreases in brush border membrane disaccharidase activities were shown to occur by day 3 after infection in the upper, mid, and distal small intestine. Goblet cell hyperplasia therefore developed before tissue damage in the distal small intestine but after damage in the upper small intestine, possibly suggesting that proliferation of goblet cells was triggered by different mechanisms in the two intestinal regions. Since disaccharidase activities returned to normal levels by day 14 in the upper and mid small intestine, it seemed that goblet cell hyperplasia persisted even after recovery of mucosal function.

Infection with $Y$ enterocolitica resulted in the rapid development (within one day) of goblet cell hyperplasia in the distal small intestine and the proximal colon of rabbits. As disease progressed, goblet cell numbers in the mid and then the upper small intestine also increased. The greatest changes in goblet cell numbers occurred where overall mucosal damage was most severe namely, in the distal small intestine and the proximal colon. Goblet cell hyperplasia persisted throughout the gut up to 14 days after infection despite recovery of normal mucosal function, elimination of infection, and clearance of inflammation in the upper and mid small intestine by that time. Thus goblet cell hyperplasia seems to be an early response to intestinal injury and remains as the mucosa recovers morphologically and functionally. By day 6 after infection goblet cell mucin became less sialylated (in the small intestine) but more sulphated (in both the small intestine and the proximal colon). In the regions of the intestine most affected by the disease (the distal small intestine and the proximal colon) additional changes in mucin carbohydrate composition occurred consistent with the presence of fewer but longer oligosaccharide chains. These events presumably arise in an attempt to protect the mucosa from further injury and to allow regeneration of the damaged epithelium. Further work is now required to identify the factors that modulate these changes in goblet cells during $Y$ enterocolitica infection and to establish how the mucus barrier is functionally affected by the alterations in mucin composition.

Financial support was provided by the Canadian Foundation for Ileitis and Colitis and the Medical Research Council of Canada. $M M$ is a Scholar of the Alberta Heritage Foundation of Medical Research.

1 Mantle M, Allen A. Gastrointestinal mucus. In: Davison JS, ed. Gastrointestinal secretion. London: Butterworths, 1989: 202-29.

2 Morrissey SM, Tymvios MC. Acid mucins in human intestinal goblet cells. F Pathol 1978; 126: 197-208.

3 Forstner J, Maxwell B, Roomi N. Intestinal secretion of mucin in chronically reserpine-treated rats. Am $\mathcal{F}$ Physiol 1981; 241: G443-50.

4 Miller HRP, Huntley JF, Dawson AMcL. Mucus secretion in the gut, its relationship to the immune response in in the gut, its relationship to the immune response in Nippostrongylus-infected rats. In: Bourne FJ, ed. Current
topics in veterinary medicine $\mathcal{E}$ animal science. London: topics in veterinary medicine $\mathcal{E}$

5 Ehsanullah M, Filipe MI, Gazzard B. Mucin secretion in inflammatory bowel disease: correlation with disease activity and dysplasia. Gut 1982; 23: 485-9.

6 Cope GF, Heatley RV, Kelleher J, Axon ATR. In vitro mucus glycoprotein production by colonic tissue from patients with ulcerative colitis. Gut 1988; 29: 229-34.

7 Wesley A, Forstner J, Qureshi R, Mantle M, Forstner J Human intestinal mucin in cystic fibrosis. Pediatr Res 1983; 17: 65-9.

8 Mantle M, Stewart G. Intestinal mucins from normal subjects and patients with cystic fibrosis. Biochem $\mathcal{F} 1989 ; 259$ : 243 and 53 .

9 Morrissey SM, Ward PM, Jayaraj AP, Tovey FI, Clark CG. Histochemical changes in mucus in duodenal ulceration. $G u$ 1983; 24: 909-13.

10 Reid PE, Culling CFA, Dunn WL, Clay MG. Chemical and histochemical studies of normal and diseased human gastrointestinal tract. II. A comparison between histologically normal small intestine and Crohn's disease of the smal intestine. Histochem F 1984; 16: 253-64.

11 Ehsanullah M, Filipe MI, Gazzard B. Morphological and mucus secretion criteria for differential diagnosis of solitary ulcer syndrome and non-specific procitis. 7 Clin Pathol ulcer syndrome
$1982 ; 35: 26-30$.

12 Filipe MI, Fenger C. Histochemical characteristics of mucins in the small intestine. A comparative study of normal mucosa, benign epithelial tumours and carcinoma. Histochem f 1979; 11:277-87.

13 Reid PE, Owen DA, Dunn WL, Ramey CW, Lazosky DA Clay MG. Chemical and histochemical studies of normal and diseased human gastrointestinal tract. III. Changes in th histochemical and chemical properties of the epithelial glycoproteins in the mucosa close to colonic tumours. Histochem $\mathcal{F}$ 1985; 17: 171-81.

14 Miller HRP, Nawa Y. Nippostrongylus brasiliensis: intestinal goblet-cell response in adoptively immunized rats. Exp goblet-cell response in
Parasitol 1979; 47: 81-90.

15 Koninkx JFJG, Mirck MH, Hendriks HGCJM, Mouwen JMVM, Van Dijk JE. Nippostrongylus brasiliensis: histochemical changes in the composition of mucins in goble cells during infection in rats. Exp Parasitol 1988; 65: 84-90.

16 Mantle M, Thakore E, Hardin J, Gall DG. Effect of Yersinio enterocolitica on intestinal mucin secretion. Am $\mathcal{f}$ Physio 1989; 256: G319-27. 
17 Pai CH, Mors V, Seemayer TA. Experimental Yersinia enterocolitica enteritis in rabbits. Infect Immun 1980; 28: 23844.

18 O'Loughlin EV, Humphreys G, Dunn I, Kelly J, Lian CJ, Pai C, et al. Clinical, morphological, and biochemical alterations in acute intestinal yersiniosis. Pediatr Res 1986;

19 O'Loughlin EV, Pai CH, Hardin JA, Gall DG. Colonic function in acute Yersinia enterocolitica infection in rabbits Clin Invest Med 1988; 11 : 366-72.

20 O'Loughlin EV, Pai CH, Gall DG. Effect of acute Yersinia enterocolitica infection on in vivo and in vitro small intestina solute and fluid absorption in the rabbit. Gastroenterology 1988; 94: 664-72.

21 Volz D, Reid PE, Park CM, Owen DA, Dunn WL. A new histochemical method for the selective periodate oxidation of total tissue sialic acids. Histochem $\mathcal{F}$ 1987; 19: 311-8.

22 Volz D, Reid PE, Park CM, Owen DA, Dunn WL. Histochemical procedures for the simultaneous visualization of neutral sugars and either sialic acid and its side chain $\mathrm{O}$-acyl variants or O-sulphate ester. I. Methods based upon the variants or O-sulphate ester. I. Methods based upon the
selective periodate oxidation of sialic acids. Histochem $\mathcal{F}$

23 Reid PE, Volz D, Park CM, Owen DA, Dunn WL. Methods for the identification of side chain $\mathrm{O}$-acyl substituted sialic acids and for the simultaneous visualization of sialic acids, its side chain $\mathrm{O}$-acyl variants and $\mathrm{O}$-sulphate ester. Histochem $\mathcal{F}$ 1987; 19: 369-8.

24 Mantle M, Thakore E. Rabbit intestinal and colonic mucins: isolation, partial characterisation, and measurement of secretion using an enzyme-liked immunoassay. Biochem Cell secretion using an enzyr

25 Chaplin MF. A rapid and sensitive method for the analysis of carbohydrate components in glycoproteins using gas-liquid chromatography. Analyt Biochem 1982; 123: 336-41.

26 Silvestri LJ, Hurst RE, Simpson L, Settine JM. Analysis of sulphate in complex carbohydrates. Anal Biochem 1982;123: 303-9.

27 Mantle M, Stewart G, Zayas G, King M. The dissulphidebond and rheological properties of intestinal mucins from normal subjects and patients with cystic fibrosis. Biochem $\mathcal{F}$ 1990; 266: 597-604.

28 Hinegardner RT. An improved flurimetric assay for DNA. Anal Biochem 1971; 39: 197-201.

29 Reid PE, Walker DC, Terpin T, Owen DA. Histochemical studies of the colonic epithelial glycoproteins of the normal studies of the colonic epithelial glycopro
rabbit. Histochem $\mathcal{F} 1988 ; 20: 533-50$.

30 Buret A, O'Loughlin EV, Curtis G, Gall DG. Effect of acute Yersinia enterocolitica infection on small intestinal ultrastructure. Gastroenterology 1990; 98: 1401-7. 